\title{
User-Centered Design Gymkhana
}

\section{Muriel Garreta-Domingo}

Universitat Oberta de Catalunya

Av. Tibidabo, 39-43

Barcelona, 08035 Spain

murielgd@uoc.edu

\section{Magí Almirall-Hill}

Universitat Oberta de Catalunya

Av. Tibidabo, 39-43

Barcelona, 08035 Spain

malmirall@uoc.edu

\section{Enric Mor}

Universitat Oberta de Catalunya

Rambla Poblenou, 156

Barcelona, 08018 Spain

emor@uoc.edu

\begin{abstract}
The User-centered design (UCD) Gymkhana is a tool for human-computer interaction practitioners to

demonstrate through a game the key user-centered design methods and how they interrelate in the design process. The target audiences are other organizational departments unfamiliar with UCD but whose work is related to the definition, creation, and update of a product or service.
\end{abstract}

\section{Keywords}

Games with a purpose, game pieces, HCI education, HCI evangelization, user-centered design, role-playing, design games, experience.

\section{ACM Classification Keywords}

H5.2. Information interfaces and presentation: Usercentered design. H5.2. Information interfaces and presentation: Training, help and documentation.

\section{Introduction}

As Twidale and Marty state, usability professionals often have to combine the roles of usability advocates, educators and practitioners [10]. Bias and Mayhew [2] addressed this issue by putting together a collection of articles on cost-justification of usability. However, the argument of cost-justification by itself is not enough to introduce user-centered design (UCD) in an

organization. As Siegel [7] explains, "success will hinge 
not on a single convincing argument, but on the many interrelated ideas we introduce to our organizations, on the kinds of relationships we build with various stakeholders, and on how we demonstrate our value to them first hand."

The Open University of Catalonia (UOC) is a completely online university with more than 40,000 students that offers 19 official undergraduate degrees as well as several graduate programs. The UOC virtual campus is an integrated e-learning environment that allows students to pursue their studies completely online with the exception of taking final exams. As a result, the virtual campus plays a key role at the UOC as it is the work tool for UOC employees, the teaching tool for faculty members, and the learning tool for students.

In such a context, UCD should play a central role in all UOC departments that define, create and implement products for the virtual campus users. Nevertheless this is still not the case today. Although the introduction of usability and $\mathrm{HCI}$ concepts in the organization started in 2002, they are still not well understood and therefore, they are not properly applied.

To date, different strategies to proselytize and teach UCD have been used: a multidisciplinary User Experience Group that gathers employees interested in UCD from different departments, internal UCD courses and sessions with external speakers, and also a portable usability lab that can be used by anyone who needs it.

All these different activities and others have been successful in transmitting the importance of usability but not yet in showing the value of following a UCD process. For example, there are several departments that run usability tests and apply an iterative design process but providers are not required to follow hi-fi prototypes when implementing the application. There are departments that hire usability consultants but bring them in just at the end of the design process. There have been projects defined to follow a UCD process which ended up being a stakeholder-centered design process that listened only to the requirements of management and influential people within the company, instead of the users.

The purpose of the gymkhana is to avoid these types of errors by promoting a better understanding of a good design process; showing the importance of understanding the end user and keeping the focus on the user as well as choosing the right methods for analyzing the users and evaluating the design.

\section{The target audience}

The UOC is a mid-size company with about 400 employees including management, faculty members and administrative and support staff. In general terms, these employees can be grouped in three user profiles depending on their relationship with UCD.

The largest group is formed by employees whose work is not directly related to the definition, creation and update of the virtual campus. For the most part, this group is unaware of the existence of UCD. Although they use the virtual campus for their everyday work, they work around its flaws and probably do not have direct contact with students.

The second group of people most likely have seen a video of a user test or attended one. This group knows 
what usability is but does not understand what UCD implies as a product development approach. Their tasks are related with the design and update of applications and/or require being in contact with students or other users of the virtual campus. Most often this group creates functionalities and applications without considering UCD and they request help of usability experts when the product is already finished and end users complain.

The third group has basic notions of usability and most common HCI methods, and is willing to think of the user at some point of the development process.

However, they lack the knowledge to put the focus on the user throughout the whole development process, to choose the right method for a specific need and to see the value of the whole process. As a consequence, they might run a user test without knowing the target user of their project, or write a survey with biased questions to validate what they think should be done.

The main target of the UCD gymkhana is this last group and, in a second term, the middle group. Even though the target audiences are people at least familiar with the concept of usability and UCD, the goal is to ensure that the game is comprehensible even for the first group.

\section{The game goals}

The UCD gymkhana idea was born after the celebration of World Usability Day (WUD) 2005. As part of the UCD diffusion goal, several activities were organized for the occasion. There were formal presentations about inhouse projects that followed the UCD process. Outside the conference room, a set of independent stations was placed where visitors could get an overview of the UCD process and methods, experience a usability test in a lab setup, and understand the importance of accessibility by using a computer with a JAWS system. This last station, where participants had to browse the Internet with the screen turned off and follow voice instructions, was the most successful of all the activities that had been organized.

The aim when designing the gymkhana was to obtain a set of engaging stations where participants can experience the different steps of a UCD process. It is structured as a game because the goal is not only to show how each project phase is accomplished individually but also how the project as a whole is put together and how these different phases relate to one another.

In summary, the purpose of the gymkhana is:

- To show the key steps of a UCD process in an enjoyable and informal setting.

- To make participants understand how these steps relate to each other.

- To give an overview of the main HCI techniques and methods.

- To illustrate that the user target and the methods used affect the end design.

\section{The game structure}

The setup of the UCD gymkhana is similar to the Interactionary, a design exercise envisioned and organized at some $\mathrm{CHI}$ conferences by Berkun [1]. The main differences being that the gymkhana is not an onstage competition and it is not addressed to designers or an $\mathrm{HCI}$ audience. In this sense, the game show 
created by Twidale and Marty [10] is closer to the goals pursued by the gymkhana. Their game illustrated usability evaluation methods; the gymkhana strives to illustrate the UCD process and techniques.

Buchenau and Fulton [3], in their paper about experience prototyping, quote the Chinese philosopher Lao Tse: "What I hear, I forget. What I see, I remember. What I do, I understand!" As mentioned, at UOC we have worked on the "hearing" and the "seeing"; the gymkhana is a way of promoting understanding by doing. Like Buchenau's and Fulton's, there are several papers on how to include "doing" in the design process by role-playing, informance design, interactive scenarios, participatory design, etc.

$[4,5,6,8,9]$. However, these papers address a different problem than the gymkhana and therefore are aimed to a different audience, pursuing different goals.

In a paper on designing exploratory design games, Brandt [4] describes various kinds of games, one of which is similar in concept to the gymkhana: "The primary aim with the negotiation and workflow oriented games is for the designers to understand existing work practice. Game boards and game pieces are produced in paper. The outcome of the game playing is often flow diagrams showing relations between people and various work task or tools." In our case, we want other company employees to understand UCD work practices using game pieces for each of the UCD phases and a game board to show the relations between the different phases and the end design.

The design problem

Like Berkun [1], we decided that a non-web problem would work best with a large audience and that a physical design of an everyday object would be better as these concepts are familiar to everyone, and the details are broad enough for everyone to follow along. This is the same principle we use when bringing outside speakers, since we have experienced that our audience is more receptive when the topics are not related to their everyday work. Therefore, in our choice of the design problem these issues played a key role and we opted for the design of a ticket vending machine. To narrow the scope, this machine would only sell tickets to the airport and it is placed in a central railroad station of Barcelona, Spain.

\section{The game stations}

The gymkhana consists of four different stations; each station representing a phase in the UCD design process: defining the users, analyzing the users' needs, designing the artifact and evaluating the resulting artifacts. Like the exploratory design games in design work [4], the players of the gymkhana do not compete. Each team goes through the stations and at the end all game boards are shown together in a separate room so that participants and other employees can evaluate the design solutions.

The WUD promoted by UPA is the background for the UCD gymkhana. The stations are one of the activities that will be available in the main reception hall during this day.

Teams are created on the spot as people walk by and show an interest in the stations. As long as possible, groups of 3 to 4 people are created with participants from different departments. To start with, they read an overall description of the game and they are given a one-page description of the design problem. 
Defining the users. The aim of this first station is to introduce the idea that good design is accomplished by thinking of the end user and that this end user is neither the designer nor all consumers. The team is presented with a set of 20 to 25 pictures of users that use the railroad station with a short demographic description. Participants are asked to pick the pictures of the people that they will design for and write down their main characteristics.

Analyzing the users' needs. The aim of this second station is to show that designers use several quantitative and qualitative methods to gather data about the chosen target. Defining the users is the first step; here they analyze their needs, wants, contexts, and limitations by choosing a maximum of three methods from the UCD toolbox.

After opening the envelopes of the selected methods, the team has to summarize the findings and write down a list of characteristics that should be considered when designing the artifact. Take the contextual inquiry method, the team has to watch a video of the railroad station where the vending machine will be placed. For benchmarking, they have pictures of other ticket vending machines already in use in the station. Other methods available in the toolbox are: in-depth interview, focus groups, surveys, log analysis, user testing and heuristic evaluation.

Designing the artifact. The goal of this station is to show that a successful design is focused on the end user. As a consequence, designers should not jump directly to the end design but they should consider the output of the previous station and follow an iterative design process. As a hint, the team is told that they can use the UCD toolbox again if they need to. The output of this station is a lo-fi prototype of the vending machine and, if the team has understood the UCD philosophy, they will have at least two different prototypes.

Evaluating the designed artifacts. At the end of the game, each team pastes the one-page output of each station on a horizontal game board. The board is divided as if it was formed by four pieces of a puzzle: the photos of the target users and key characteristics, required characteristics of the artifact according to the user analysis and the methods used, the first lo-fi prototype, and a second prototype, the result of evaluating the first prototype.

Game boards are displayed in a room where participants and other company employees can observe the different designs and UCD processes. In order to evaluate the designs, participants and observers have a questionnaire that contains questions such as "Does the design take into account the context of use?" or "Did the team evaluate their first design solution?"

\section{Testing the UCD gymkhana}

In order to evaluate the game structure and its different stations, a test with a small group was run. Half of the people invited to participate were $\mathrm{HCI}$ experts and the other half was familiar with UCD but had never applied a full UCD process. The groups were mixed and had to go through each of the four stations of the game: defining the target user, analyzing its needs, designing, and evaluating. It was very rewarding to see the different groups making different decisions at each of the stations. The groups defined different user targets, selected different methods and ended up with different designs because they designed 
for their users. In this sense, the test proofed that the game is useful to show how phases relate to each other and that designs depend on characteristics of the end user and the methods used. Through the post-game questionnaire we gathered that all participants considered the game useful to show the value of UCD methods and process and that it was an enjoyable, refreshing and enriching experience. We also obtained feedback on areas to improve, such as a tighter control

\section{Acknowledgements}

We thank Michael Muller from IBM Research for being our mentor.

This work has been partially supported by a Spanish government grant under the project PERSONAL

(TIN2006-15107-C02-01) and by the Campus project promoted by the Generalitat de Catalunya.

\section{References}

[1] Berkun, S. Interactionary: Sports for design training and team building. http://www.scottberkun.com/dsports.

[2] Bias, R. G. and Mayhew, D. J. (Eds.). Cost justifying Usability: An Update for the Internet Age. Morgan Kaufmann, San Francisco, CA, USA, 2005.

[3] Buchenau, M. and Fulton Suri, J. Experience Prototyping. Proceedings on Designing Interactive Systems, ACM Press (2000), 424-433.

[4] Brandt, E. Designing Exploratory Design Games: A Framework for Participation in Participatory Design? Proceedings Participatory Design Conference. ACM Press (2006), 57-66. of time for each station and a less technical and ambiguous description of the phases and methods.

We are confident that with these slight improvements, the gymkhana will be a successful tool to show UCD process and methods to an audience of non-experts but whose tasks are related to the definition, creation, and update of a product or service. We will test it again on November $14^{\text {th }}$ during World Usability Day 2006.

[5] Burns, C., Dishman, E., Verplank, W. and Lassiter, B. Actors, Hairdos \& Videotape - Informance Design. Proceedings of CHI 1994, ACM Press (1994), 119-120.

[6] Klemmer, S. R., Hartmann, B. and Takayama, L. How Bodies Matter: Five Themes for Interaction Design. Proceedings on Designing Interactive Systems, ACM Press (2006), 140-149.

[7] Siegel, D. The Business Case for User-Centered Design: Increasing Your Power of Persuasion. interactions 10, 3 (2003) 30-36.

[8] Simsarian, K. T. Take it to the Next Stage: The Roles of Role Playing in the Design Process. Proceedings of CHI 2003, ACM Press (2003), 10121013.

[9] Svanaes, D. and Seland, G. Putting the Users Center Stage: Role Playing and Low-fi Prototyping Enable End Users to Design Mobile Systems. Proceedings of CHI 2004, ACM Press (2004), 479-486. [10] Twidale, M. B. and Marty, P. F. Come On Down! A Game Show Approach to Illustrating Usability Evaluation Methods. interactions 12, 6 (2005), 24-27. 